\title{
The lateral cerebral peduncle: Its functional significance for the acquisition of visual and kinesthetic discriminations in the rat*
}

\author{
MARSHA A. HOWZE† \\ Louisiana State University, Baton Rouge, Louisiana 70115
}

\begin{abstract}
Previous studies have failed to support the theory of transcortical connections as the me chanism of sensorimotor integration and a subcortical pathway has been implicated. The purpose of this study was to demonstrate the significance of the lateral portion of the cerebral peduncle for the acquisition of visual pattern discrimination habits and to show its specificity for visual tasks. Twenty-two albino rats received bilateral lesions in the cerebral peduncle. Ten rats served as sham-operate controls. Following a 2-week recovery period, all Ss were overtrained on both a horizontal-vertical visual discrimination problem and an inclined-plane kinesthetic discrimination problem. A three-way analysis of variance with repeated measures indicated that the Ss did not differ with respect to the number of errors prior to the attainment of criterion on either problem. The analysis did indicate, however, that the experimental animals were inferior to the control rats in the number of days required to reach criterion, and acquisition of the visual problem required more days than acquisition of the kinesthetic problem. The Ss did not differ in the percentage of correct responses made during overtraining on either problem. It was also found that no significant relationship existed between the performance on the visual or kinesthetic problem and the amount of damage to the cerebral peduncle, substantia nigra, pedunculo-nigral area, or total damage to the brain. These results are interpreted as support of the theory of the existence of a mesencephalic mechanism for the integration of sensory, motor, attentional, and emotional-motivational systems and points to the cerebral peduncle as an important corticoreticular pathway in that system.
\end{abstract}

The mechanism through which visual impulses exert their influence upon the motor system remains unknown. An explanation of the visual-motor integrating mechanism in terms of transcortical connections have been discredited. Perhaps the most convincing evidence is the finding that rats are still able to perform a visual discrimination following bilateral removal of the striate cortex (Lashley, 1929). Penfield (1954) reports that, even following removal of gyri immediately surrounding the precentral gyrus, patients are able to accomplish movements based on visual, auditory, or remembered information. Lashley and Frank (1934) report that rats are able to execute visual pattern discriminations following lesions to the visual association cortex surrounding the striate area. Studies have also found that monkeys are able to open latches with the same speed exhibited preoperatively following removal of the motor cortex (Lashley, 1924). Meyers, Sperry, and McCurdy (1962) report that studies with monkeys and cats do not support a direct functional cortico-cortical connection between the visual and the motor cortex.

Clark (1942) expressed an alternative to the notion of a transcortical integrative mechanism: "If the

*This research was submitted as the dissertation for the doctoral degree in the Department of Psychology at Louisiana State University and was supported through department funds. The author wishes to thank Robert Thompson for his assistance and criticism and Beverly Edwards for typing the manuscript.

tPresent address: Psychology Service, Veterans Administration Hospital, 1601 Perdido St., New Orleans, Louisiana 70146. geniculo-striate organization can provide the anatomical basis for visual reactions independently of surrounding cortical areas, it is clear that there must exist efferent connexions through which the visual cortex is brought into relation with motor mechanisms of the brain stem and spinal cord [p. 228]."

Within the last decade, special consideration has been given to those structures receiving occipitofugal projections with regard to their function in visually guided behavior. Nauta and Bucher (1954) and Krieg (1947) report that the striate cortex sends projections through the lateral portion of the internal capsule and cerebral peduncle to the thalamus (dorsal and ventral lateral geniculate nuclei and nucleus lateralis posterior thalami), subthalamus, pretectal area, superior colliculus, and rostral pons. In addition, Valverde (1962) has described an occipitoreticular pathway which descends from the visual cortex through the lateral cerebral peduncle and, at approximately the level of the substantia nigra, begins to leave the peduncle at right angles to terminate in the nucleus cuneiformis of the mesencephalic reticular formation and the nucleus reticularis pontis oralis.

Using the lesion technique, all areas of this pathway have recently been studied in relation to their significance in the execution of visual pattern discriminations. The evidence points to Valverde's (1962) occipitoreticular pathway as the critical link between the visual receiving areas of the cortex and the 
motor areas of the brainstem. The evidence is as follows: (a) ablation of the striate cortex prevents acquisition (Horel, Bettinger, Royce, \& Meyer, 1966) and retention (Horel et al, 1966; Thompson, 1969) of a visual pattern discrimination habit; (b) bilateral lesions to the lateral cerebral peduncle produce profound losses in retention of a horizontal-vertical discrimination habit (Thompson \& Craddock, 1972; Thompson, Howze, \& Pucheu, 1973); (c) knife cuts through the midbrain which disconnect the cerebral peduncle and the midbrain reticular formation significantly impair postoperative performance on the same problem (Howze \& Thompson, 1972); (d) a significant correlation has been reported between retention deficits on a pattern discrimination problem and damage to the cerebral peduncle (Thompson et al, 1973); (e) lesions to the nucleus cuneiformis of the mesencephalic reticular formation produce significant deficits in the performance of the pattern problem (Thompson, 1965; Thompson et al1 Petit, 1972); (f) lesions to the nucleus reticularis pontis oralis also have a detrimental effect on the postoperative performance of a visual pattern discrimination habit (Thompson \& Henderson, 1971); and (g) the deficits resulting from lesions of knifecuts to the cerebral peduncle are greater on the visual discrimination problem than the deficits on a kinesthetic discrimination problem of equal difficulty (Thompson \& Craddock, 1972; Howze \& Thompson, 1972).

The purpose of the current study was to test further the significance of Valverde's (1962) occipitoreticular pathway in the execution of visually guided behavior. It was expected that lesions to the lateral cerebral peduncle would produce deficits in the rate of acquisition of a horizontal-vertical problem, but would have no significant effect on the acquisition of a kinesthetic discrimination problem of equal difficulty. This latter expectation is based on (a) an earlier investigation (Lashley, 1929) which showed deficits in the kinesthetic discrimination following lesions to the sensorimotor, but not occipital, cortex; (b) Valverde's (1962) demonstration that efferent fibers from the sensorimotor cortex descend through the medial portion rather than the lateral portion of the cerebral peduncle; and (c) previous neu ropsychological reports (Thompson \& Craddock, 1972; Howze \& Thompson, 1972) that damage to the lateral cerebral peduncle produces greater deficits on the retention of a visual than a kinesthetic discrimination problem.

The experiment reported here was an improvement over earlier studies on the cerebral peduncle in that it employed a within-Ss design, training all Ss on both visual and kinesthetic problems. Thompson and Craddock (1972) and Howze and Thompson (1972) used a between-Ss design and therefore used two separate groups of Ss for the two tasks.

Because lesions to the lateral cerebral peduncle invariably impinge upon the lateral substantia nigra and terminal nuclei of the accessory optic system (see Hayhow, Webb, \& Jervie, 1960), the significance of damage to these structures in performing the discrimination tasks will also be investigated. In a previous study, Schweigerdt (1969) identified the substantia nigra as a critical area for the acquisition of habits based on visual cues. Thompson et al (1973), however, found that bilateral damage to the dorsal and lateral terminal nuclei did not impair retention of a visual discrimination habit.

In an attempt to clarify the nature of the learning deficit, 50 overlearning trials will be given on each problem following the attainment of criterion. A sensory deficit may be ruled out if the Ss attain criterion on the visual task and maintain a high level of performance during the overtraining phase. On the other hand, poor performance during the latter period may indicate a deficit in sensory and/or attentional mechanisms.

\section{METHOD}

\section{Subjects}

Forty-eight adult male albino rats of the Wistar strain were used. The Ss were divided into two groups: Group VK acquired the visual problem first, followed by the kinesthetic problem; Group KV learned the problems in the reverse order.

Ten Ss servid as sham-operate controls, and 38 rats were subjected to bilateral lesions of the midbrain. Of the experimental animals, two died during the 2-week recovery period following surgery, three died during training, and one was dropped from the experiment because of atypical behavior. Of the 42 animals which completed the experiment, 10 were eliminated because their lesions impinged upon the hippocampus and/or lateral geniculate nucleus of the thalamus. Thus data are reported on 22 experimental and 10 control Ss.

\section{Surgery}

All operations were performed under deep chloral hydrate anesthesia. In the case of the sham-operate control Ss, only the initial incision in the scalp was made. Bilateral one-stage multiple lesions were stereotaxically placed in the lateral half of the cerebral peduncle of the experimental rats according to the coordinates $1.4 \mathrm{~mm}$ anterior, $2.5 \mathrm{~mm}$ lateral, $7.5 \mathrm{~mm}$ ventral, and $1.4 \mathrm{~mm}$ anterior, $3.0 \mathrm{~mm}$ lateral, 7.0 ventral (Massopust, 1961). The lesions were produced by passing a $2-\mathrm{mA}$ current for $5 \mathrm{sec}$ through a stainless steel anodal electrode with $.5 \mathrm{~mm}$ of the tip exposed.

Prior to acquisition of the two discrimination problems, a stainless steel safety pin was inserted into the ears of each $S$. These safety pins later held iridescent tape, used to determine the location of the rat in the kinesthetic apparatus. In addition, vibrissae were trimmed, when necessary, throughout the experiment to eliminate tactual cues.

\section{Visual Habit}

Apparatus. All Ss were trained in a two-choice Thompson-Bryant (1955) visual-discrimination box with escape (or avoidance) of footshock serving as the motive. Details of the apparatus have been presented elsewhere (Thompson, 1969). Two sets of stimulus cards were used. For preliminary training, two gray cards of equal brightness were used. The stimulus cards used in acquisition were patterned and contained black and white stripes. The striations were $1 / 2$ in. wide and both cards were equal in total black and white areas. The patterned cards were 
rotated so that horizontal or vertical stripes appeared in each window.

Preliminary Training. Prior to surgery, the method of successive approximations was used to train all animals to leave the startbox, traverse the choice chamber, displace one of the two gray cards, and enter the goalbox. Following surgery and a 2-week recovery period, each rat was given refresher trials on displacing cards and entering the goalbox.

Acquisition. The Ss were required to learn a simultaneous visual pattern (horizontal-vertical) discrimination problem by displacing the horizontally striped card and avoiding the vertically striped card. A pproach to within 3 in. of the vertically striped card was automatically punished by a $2-\mathrm{mA}$ footshock, and the $S$ was then required to correct his error. Brief footshock was also applied if the $S$ did not leave the startbox within $5 \mathrm{sec}$ or failed to make a choice between the stimulus cards within $15 \mathrm{sec}$. The position of the horizontal and vertical cards was varied in a prearranged "random" sequence such that a card did not appear in the same position more than two successive trials, and the cards appeared in both the left and right positions four times each session. Each $S$ received eight trials per day with an intertrial interval of $60 \mathrm{sec}$ until the criterion of 15 correct responses were made on 2 consecutive days. Following the attainment of criterion, the $S$ was given 10 overtraining trials per day for 5 days. Training on the visual habit was terminated if a rat failed to reach criterion after 20 days of acquisition.

\section{Kinesthetic Habit}

Apparatus. An inclined box similar to that described by Thompson, Duke, Malin, and Hawkins (1961) was used to establish the kinesthetic-discrimination habit. Escape (or avoidance) of footshock was the motive used in this apparatus. Briefly, the apparatus consisted of a single-unit T-maze fastened to a platform which could be tilted 95 deg laterally. Displacement of the card at the entrance to each goalbox admitted the rat to the goalbox.

Preliminary Training. During preliminary training, the apparatus remained level and Ss were trained in an illuminated room. The training procedure was similar to that employed using the visual apparatus. Following surgery and a 2 -week recovery period, each $S$ was given refresher trials on leaving the startbox and entering the goalbox. These trials were conducted in the dark.

Acquisition. On the kinesthetic discrimination problem, the $\mathrm{S}$ was required to choose the arm of the T-maze inclined upward, and to avoid the arm inclined downward in order to avoid footshock. The training and overtraining procedures were the same as that employed in establishing the visual habit. To avoid the use of the visual cues, the Ss were trained in the dark. ${ }^{2}$ Prior to training on each day, a piece of tape painted with iridescent paint was placed on the safety pin in the rat's ear. When the iridescent marked on the rat's head reached the iridescent marked outside the downward-sloping arm (and out of the rat's view) $3 \mathrm{in}$. in front of the entrance to the goalbox, an error was judged to have been comitted and footshock was applied.

\section{Histology}

Following overtraining on both the visual and kinesthetic discrimination problems, each $\mathrm{S}$ was sacrificed with an overdose of Numbutal and perfused through the vascular system with $10 \%$ Formalin. The brain was removed and hardened in 10\% Formalin for $24 \mathrm{~h}$. Each brain was frozen and sectioned frontally at 90 microns. Every third section through the lesioned area was photographed at $10 \mathrm{X}$ with a Leitz enlarger.

The lesions of each brain were transcribed on worksheets (enlarged drawings of brain sections at various levels) to facilitate analysis of the locus and size of damage and the structures involved. Only the central necrotic zone (vacuolated and severely coagulated areas) was considered in determining the extent of damage. The extent of damage to the cerebral peduncle and substantia nigra and the total size of the lesion were calculated by the use of transparent grids. Only bilateral damage was considered, and only damage at nigral levels from the onset of the substantia nigra to the level of the third nerve was calculated. $^{3}$

\section{Measures of Performance}

Two types of error scores were calculated from the original learning records. "Criterion run" errors are defined as the number of errors committed prior to the attainment of 15 correct responses on 2 consecutive days. "Significant run" errors indicate the number of errors made prior to the earliest attainment of a perfect (Grant, 1946) or near perfect (Runnels, Thompson, \& Runnels, 1968) series of correct responses that has a probability of occurrence of less than .05 . In general, the significant run yields a lower number of errors and is therefore considered to be a more sensitive measure of learning (Thompson, 1969). The criterion run indicates the S's ability to maintain a high level of accurate performance.

\section{Statistical Analysis}

To determine the effect of cerebral peduncle lesions on the acquisition of the visual and kinesthetic problems, the data were analyzed using a 2 by 2 by 2 analysis of variance with repeated measures on the third factor (case II, Winer, 1962).

The correlations between the amount of cerebral peduncle, substantia nigra, and total damage and the significant run and criterion run error scores were determined by the Pearson produce-moment correlation coefficient (Winer, 1962).

\section{RESULTS}

\section{Description of Lesions}

Figures 1 and 2 show photographs of unstained brain sections of two rats containing lesions representative of those sustained by the experimental animals in this study. The Ss with lesions sustained from $0 \%-55 \%$ damage to the cerebral peduncle (mean $=25.8 \%$ ), $3 \%-72 \%$ destruction of the substantia nigra $($ mean $=33.7 \%), 2 \%-60 \%$ total damage to the substantia nigra and cerebral peduncle $($ mean $=29.3 \%$ ), and $2 \%-15 \%$ total damage to the midbrain between the anterior pole of the substantia nigra and the level of the third cranial nerve $($ mean $=8.5 \%)$.

Three rats also sustained damage to the subthalamus, and 14 animals received lesions which impinged upon the accessory optic system. The performance of these Ss will be discussed later in this report.

\section{Original Learning}

The mean number of errors to criterion for both the visual and kinesthetic problems is presented in Table 1. A three-way analysis of variance with repeated measures (Winer, 1962) was computed for the errors necessary to master the visual and kinesthetic problems. ${ }^{4}$ There were no overall differences between the Ss attributable to order (VK vs KV), group (experimental vs control), or problem (visual vs kinesthetic) or interactions of these main effects.

Table 1 also presents the mean number of days required to attain criterion on the visual and kinesthetic tasks. A three-way analysis of variance with repeated measures (Winer, 1962) was also computed for the days-to-criterion measure. A summary table of this 


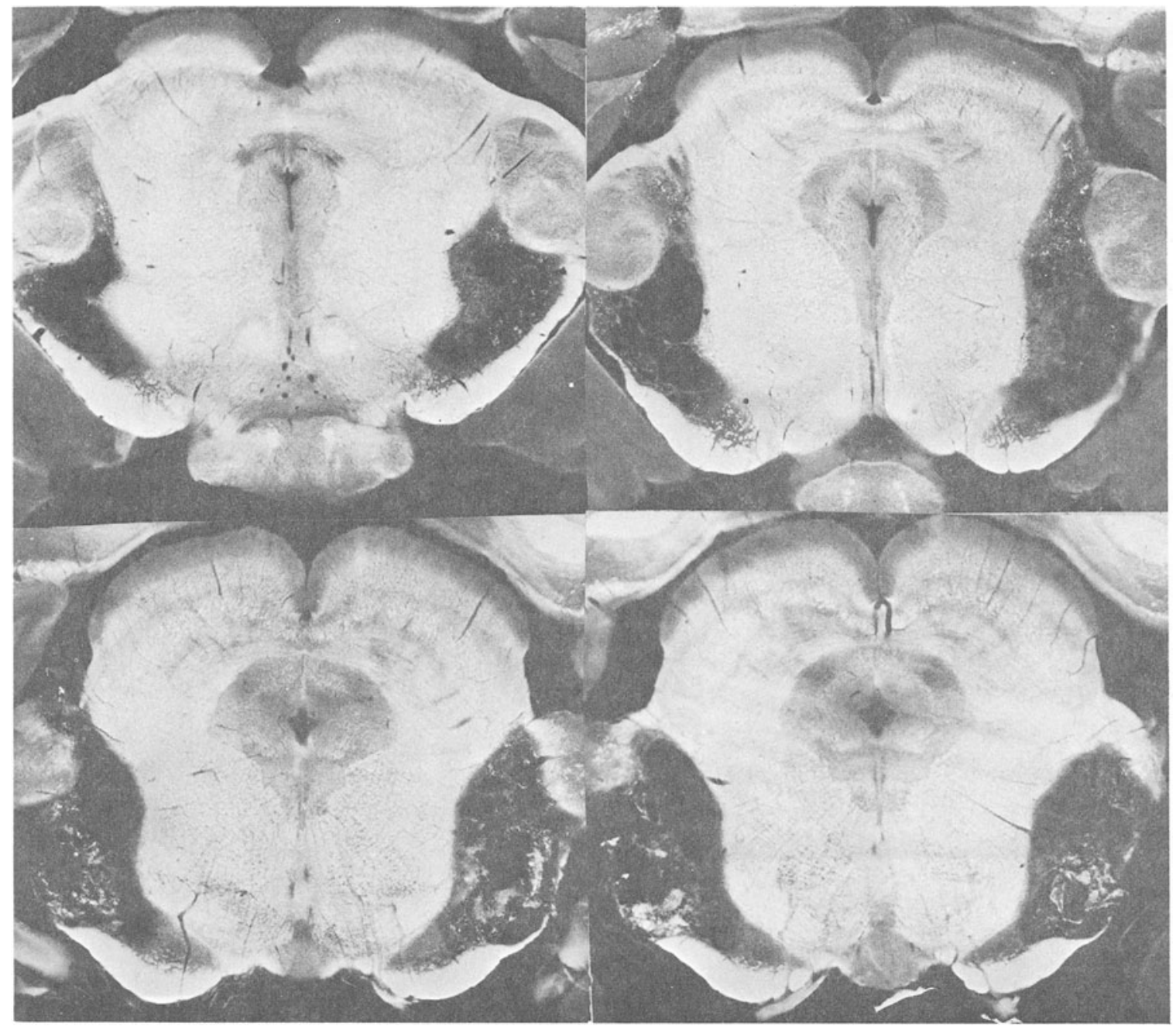

Fig. 1. Photographs of four unstained sections from the brain of $\mathrm{s}$ VK-12. This animal committed 55 errors in 17 days and earned $92 \%$ correct responses during overtraining on the visual problem. The rat committed 12 errors in 3 days and made $92 \%$ correct responses on the kinesthetic problem. He sustained $55 \%$ peduncular and $65 \%$ nigral damage in addition to damage to the dorsal and lateral terminal nuclei of the accessory optic system.

analysis is presented in Table 2 . The analysis reveals no overall differences attributable to the order in which the visual and kinesthetic problems were mastered and none of the interactions involving the order variable were significant. The F-ratio for both the group and problem main effects were statistically significant. The experimental group required more trials to master the tasks than the control group and the visual task took longer to acquire than the kinesthetic task. The Group by Problem interaction was also significant, since the experimental group required more trials to reach criterion on the visual problem than were required on

Table 1

Mean Number of Errors and Days to Criterion and Mean Percentage Correct Responses During Overtraining

\begin{tabular}{|c|c|c|c|c|c|c|c|}
\hline & \multirow[b]{2}{*}{$\mathrm{N}$} & \multicolumn{3}{|c|}{ Visual } & \multicolumn{3}{|c|}{ Kinesthetic } \\
\hline & & Errors & Days & Overtraining & Errors & Days & Overtraining \\
\hline $\begin{array}{l}\text { Group C } \\
\text { Group E }\end{array}$ & $\begin{array}{l}10 \\
22\end{array}$ & $\begin{array}{l}20.20 \\
27.95\end{array}$ & $\begin{array}{l}6.40 \\
9.10\end{array}$ & $\begin{array}{l}98.20 \\
94.10^{*}\end{array}$ & $\begin{array}{l}22.20 \\
23.00\end{array}$ & $\begin{array}{l}6.30 \\
6.64 \\
\end{array}$ & $\begin{array}{l}95.60 \\
95.91 \\
\end{array}$ \\
\hline
\end{tabular}

${ }^{*} N=21$ : One subject failed to reach criterion on the visual problem and was not trained in the overtraining phase of that problem. 


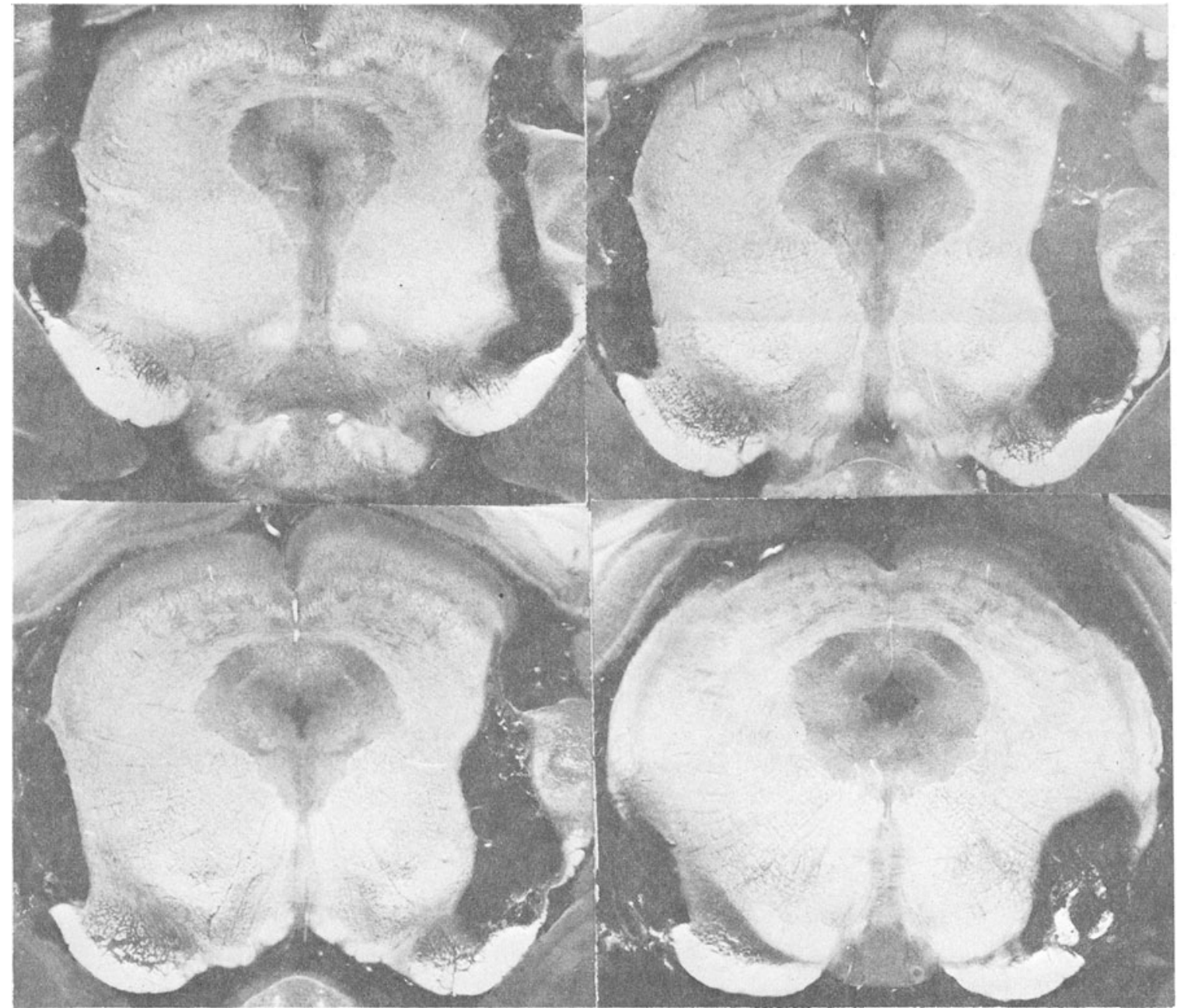

Fig. 2. Photographs of four unstained sections from the brain of S VK-12. This animal committed 38 errors in 11 days and earned $92 \%$ correct responses during overtraining on the visual problem. He made 31 errors in 9 days and made $96 \%$ correct responses on the kinesthetic problem. The rat sustained $22 \%$ damage to the substantia nigra, $24 \%$ damage to the cerebral peduncle, $6 \%$ total damage to the midbrain and damage to the accessory optic system.

the kinesthetic problem. Figure 3 illustrates the mean number of days required by each group to reach successive criteria of 8 correct responses out of 16 trials, 9 correct responses out of 16 trials, etc., until the criterion of 15 correct responses out of 16 trials was attained. The first point on the graph was obtained by computing the mean number of correct responses made by each group during the first 2 days of original learning. All other points represent the mean number of days required by a given group to attain a specific criterion. As Fig. 3 illustrates, although the experimental and control groups made approximately the same number of correct choices on both the visual and kinesthetic problems during the first 2 days of training, the experimental group took longer to attain successive criteria on the visual problem than on the kinesthetic task and longer than the control group on either the visual or kinesthetic problems. This difference became more evident after the criterion of 10 correct responses

Table 2

Analysis of Variance Source Table for the Dependent Variable Days to Criterion

\begin{tabular}{lrrr}
\hline Source & df & F & p \\
\hline Order & 1 & .79 & n.s. \\
Group & 1 & 5.75 & $<.05$ \\
Order by Group & 1 & .04 & n.s. \\
Animal (Order by Group) & 28 & .98 & n.s. \\
Problem & 1 & 4.75 & .035 \\
Order by Problem & 1 & 3.75 & n.s. \\
Group by Problem & 1 & 4.11 & .0499 \\
Order by Group by Problem & 1 & .74 & n.s. \\
Error & 28 & & \\
\hline
\end{tabular}




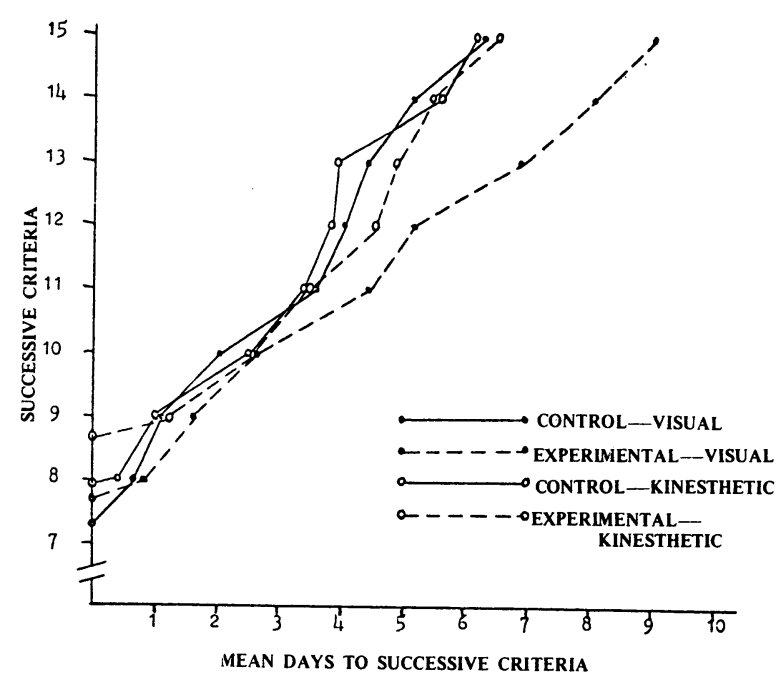

Fig. 3. Mean days to successive criteria for experimental and control Ss on the visual and kinesthetic problems.

in 16 trials was reached, with the final result that the experimental group required almost $1 \frac{1}{2}$ times as long to reach this criterion on the visual problem as the control group required on either task.

It should be noted that differential performance by the experimental group on the visual and kinesthetic problems cannot be attributed to a difference in difficulty of the two problems. The control group required a mean of 6.4 and 6.3 days to reach criterion on the visual and kinesthetic problems, respectively. A $t$ test revealed that there was no significant difference between the two means.

\section{Overtraining}

The mean percent correct responses achieved during overtraining is shown in Table 1. An analysis of variance with repeated measures (Winer, 1962) indicates that there were no overall differences in the percentage of correct responses made by the Ss during overtraining attributable to order in which the problems were acquired, the presence or absence of a brain lesion, or the problem on which overtraining was measured. In addition, the interactions between these three factors were not significant.

\section{Correlation Between Performance and Brain Damage}

The Pearson product-moment correlation coefficient (r) (Winer, 1962) was computed to determine the relationship between performance on the visual and kinesthetic problems and damage to the substantia nigra, cerebral peduncle, pedunculonigral area, and total damage to the midbrain. There was no significant relationship between the number of errors to criterion on either the visual or kinesthetic problem and the extent of damage to these structures. Also, no correlation existed between days required to attain criterion and damage to these mesencephalic structures. There was no significant relationship between the percentage of correct responses made during overtraining on either task and the substantia nigra, cerebral peduncle, pedunculonigral area, or total midbrain damage.

\section{Ss with Extrapedunculonigral Damage}

Fourteen of the 22 experimental animals sustained bilateral damage to the accessory optic system. Rats with damage to either the dorsal terminal nucleus or lateral terminal nucleus or both of these structures reached criterion on the visual task after committing a mean of 26.0 errors in 9.9 days and attained criterion on the kinesthetic problem after 22.4 errors in 6.6 days. Ss without damage to the accessory optic system committed an average of 26.1 errors in 9.0 days prior to the attainment of criterion on the visual problem and 20.5 errors in 6.8 days on the kinesthetic problem. Comparisons of original learning performance of Ss with and without damage to the accessory optic system by the use of $t$ tests indicates that differences in performance between the experimental and control zroups on the two problems cannot be attributed to damage to this system. Also, Ss with accessory optic system damage did not differ significantly from Ss without damage to this system on overtraining. Ss with lesions to the accessory optic system earned $93.0 \%$ and 95.4\% correct responses on the visual and kinesthetic problems, respectively; rats without accessory optic-system damage made $94.8 \%$ correct responses on the visual problem and $96.7 \%$ correct performance on the kinesthetic task.

Three rats sustained damage to the subthalamic area. These animals reached criterion on the visual problem after 22,31 , and 43 errors in 7, 11, and 15 days. They made $88 \%, 92 \%$, and $96 \%$ correct responses on the visual task during overtraining. On the kinesthetic problem, they attained criterion after committing 13,17 , and 33 errors in 3, 5, and 8 days and made $92 \%, 100 \%$, and $100 \%$ correct responses during overtraining. Thus their performance was well within the range of performance of experimental animals without subthalamic damage.

\section{Other Behavioral Observations}

During the postoperative recovery period, some Ss exhibited circling, head canting, hyperemotionality, obstinate progression, and aphagia. These symptoms were transient, however, and usually disappeared by the end of the first week of recovery. At no time did animals display any sign of hypokinesis, motor weakness, or pupillary disturbances. By the tirhe acquisition commenced, all Ss were gaining weight, walking in a straight line, exploring the observation table, and exhibiting good startle and orienting reflexes. Experimental Ss were virtually indistinguishable from control Ss in terms of general behavior, emotional 
reactions to shock, general orientation toward the stimulus cards, and willingness to enter the goalbox. In most cases, the distinction between experimental and control animals could not be made until autopsy. This behavior is not in agreement with the behavior of Ss in studies conducted by Thompson and Craddock (1972) and Thompson et al (1973). In the latter two studies, rats exhibited exaggerated startle reflexes to tactile stimuli around the head area and auditory stimuli. Since the lesions in this and previous studies are comparable, there is no known explanation for this discrepancy.

\section{DISCUSSION}

The results of this study support the hypothesis that the integrity of the lateral portion of the cerebral peduncle is necessary for the normal performance of visual discrimination tasks. The support for this hypothesis is based on the finding that rats with lesions to the lateral portion of the cerebral peduncle were significantly inferior to control Ss in the number of days required to reach criterion on a horizontal-vertical discrimination task. The data also support the hypothesis that these deficits in acquisition are restricted to visual, as opposed to kinesthetic, tasks. This finding is in agreement with lesion studies of Thompson and Craddock (1972) and Thompson et al (1973), which demonstrated the significance of the lateral cerebral peduncle for the retention of habits based on visual cues.

It is interesting to note that the deficit in acquisition of the visual habit by the experimental rats is in terms of the number of trials (expressed in days) required for mastery of the problem, and not in terms of the number of errors to criterion, as was found in previous investigations (Thompson \& Craddock, 1972; Thompson et al, 1973). Lashley (1935) also found that rats with striate lesions committed approximately the same number of errors as normal animals in the acquisition of a visual discrimination problem.

It may be argued that the deficits found are a result of attentional, motivational, or sensory deficits. However, this argument is not supported in light of the finding that the experimental Ss were able to perform as well as controls on the visual overtraining, and the deficit was not found on the kinesthetic task.

The finding that there existed no significant relationship between performance on the visual task and the amount of cerebral peduncle or pedunculonigral damage is in agreement with Lashley (1935). He reports that there is no significant correlation between the extent of striate lesions and the number of errors initially required to acquire a brightness discrimination. However, a significant relationship does exist between the extent of damage to the striate cortex and retention of the brightness habit. The present study is not in agreement with Thompson et al (1973), who found significant positive correlations between cerebral peduncle damage and retention of a horizontal-vertical discrimination, and combined cerebral peduncle and substantia nigra damage and retention deficits. In accordance with an earlier study (Thompson et al, 1973), there was no significant relationship between substantia nigra damage or total damage to the midbrain and performance of the visual habit.

Those familiar with the lesion method are well aware of the fact that damage is seldom restricted to the structure under investigation. In this and previous studies, lateral peduncular lesions also impinged upon the substantia nigra, reticular formation, and, in some cases, the accessory optic system and subthalamic area. The results of this and previous studies imply that it is damage to the lateral peduncle, and not overlying structures, which is responsible for deficits in performance of the visual pattern discrimination tasks: (a) First of all, an earlier report (Thompson et al, 1973) noted the significant correlation between the amount of damage to the cerebral peduncle and combined cerebral peduncle and substantia nigra damage and the loss in retention of the visual pattern discrimination habit. The correlation between substantia nigra damage and the loss in retention of the visual task was not statistically significant. In addition, Schweigerdt (1969) reports that Ss with lesions to the lateral substantia nigra similar to those produced in this study were comparable to control animals in rate of acquisition of the same task. (b) In agreement with another report (Thompson et al, 1973), there was no correlation between the size of the lesions produced and performance on the visual task. (c) Three Ss sustained lesions to the subthalamic area, a region the integrity of which is believed to be important for normal performance on a task based on visual cues (Thompson, 1969). The lesions of all three Ss were remarkably similar, and the performance of two of the rats with subthalamic damage was within the range of the performance of the control Ss. (d) Fourteen rats also received lesions which impinged upon the accessory optic system. Thompson et al (1973) report that lesions to the medial geniculate nucleus which destroy the dorsal and/or lateral terminal nuclei of the accessory optic system perform much like normal Ss in the retention of visual tasks. In this study, Ss with lesions to any part of the accessory optic system did not differ in performance from lesioned Ss without accessory optic system damage, thus supporting previous findings.

Although speculative, the present study suggests that the cerebral peduncle is a pathway by which visual impulses from the occipital cortex reach the midbrain, where they are integrated with motor, emotional-motivational, and other sensory information. The results may be considered in light of Penfield's (1952) centrencephalic theory and Thompson's (1965) theory which emphasizes the role of the ventral mesencephalon in the mediation of learned behavior. Briefly, Penfield $(1952,1954)$ hypothesizes that there 
exists a "ganglionic area" located within the di-, mes-, and rhombencephalon which records man's current perceptions (Mechanism A) and functions in the integration of sensory and motor systems, acquired skills of speech and manual dexterity, and recollection of past experiences (Mechanism B). Penfield believes that stimulation of the cortex reproduces the actual past, because the steady pressure of impulses applied by the electrode causes "barriers" to open in a pattern that was originally laid down by the effect of impulses delivered to the cortex from Mechanism B at the time of the original experience. Thus, Penfield might argue that the deficit in acquisition of the visual task was a sensory deficit because the connection between the visual sensory cortex and the centrencephalic system in which the permanent record of the visual experiences is laid down have been disconnected, that connection being the cerebral peduncle. No argument can be given here against terming the deficit a "sensory" deficit, in the context of Penfield's theory. The results of the study presented here are also consistent with Thompson's (1965) theory, which suggests that formation of the memory trace at the terminal endings of the occipito-fugal pathway subserving the learned response. In this case, the connection between the cortex and the memory trace in the mesencephalon would be the cerebral peduncle.

Certainly, the study reported here lends support to the centrencephalic theory and Thompson's (1965) ventral mesencephalic theory. Repeated studies have shown that lesions in the ventral mesencephalon produces deficits in visual (Petit, 1972; Thompson, 1965, 1969; NcNew, 1967), kinesthetic (Thompson, Lukaszewska, Schweigerdt, \& McNew, 1967) and auditory (Thompson, Rich, \& Langer, 1964) discriminations. It is speculated that the cerebral peduncle is the "link" to Mechanism B, serving in attention to visual cues, visual-motor integration, or storage and retrieval of visual information.

\section{REFERENCES}

Box, G. E. P. Non-normality and tests on variances. Biometrica, $1953,40,318-335$.

Clark, W. E. LeG. The visual centers of the brain and their connections. Physiological Review, 1942, 22, 205-232.

Grant, D. A. New statistical criteria for learning and problem solution in experiments involving repeated trials. Psychological Bulletin, 1946, 43, 558-561.

Hayhow, W. R., Webb, C., \& Jervis, A. The accessory optic fiber system in the rat. Journal of Comparative Neurology, 1960 115, 187-215.

Horel, J. S., Bettinger, L. A., Royce, G. J., \& Meyer, D. R. Role of neocortex in the learning and relearning of two visual habits by the rat. Journal of Comparative \& Physiological Psychology, 1966, 61, 66-78.

Howze, M. A., \& Thompson, R. Disconnecting occipitoreticular projections: Amnestic effects on a visual habit in the rat. Psychonomic Science, 1972, 27, 143-145.

Krieg, W. J. S. Connections of the cerebral cortex: I. The albino rat. C. Extrinsic connections. Journal of Comparative Neurology, 1947, 86, 267-394.

Lashley, K. S. Studies of cerebral function in learning: V. The retention of motor habits after destruction of the so-called motor areas in primates. Archives of Neurology \& Psychiatry, $1924,12,249-276$.
Lashley, K. S. Brain mechanisms and intelligence. Chicago: University of Chicago, 1929.

Lashley, K. S. The Mechanism of vision. XII. Nervous structures concerned in habits based on reactions to light. Comparative Psychology Monographs, 1935, 11, 43-79.

Lashley, K. S., \& Frank, M. The mechanism of vision. X. Post-operative disturbances of habits based on detail vision in the rat after lesions to the cerebral visual areas. Journal of Comparative Psychology, 1934, 17, 355-394.

Massopust, L. E. Stereotaxis atlases: A. Diencephalon of the rat. In D. E. Sheer (Ed.), Electrical stimulation of the brain. Austin: University of Texas Press, 1961.

McNew, J. J. Role of the red nucleus in visually guided behavior in the rat. Journal of Comparative \& Physiological Psychology, 1968, 65, 282-289.

Meyers, R. E., Sperry, R. W., \& McCurdy, N. M. Neural mechanisms in visual guidance of limb movement. Archives of Neurology, 1962, 7, 165-202.

Nauta, W. J. H., \& Bucher, V. M. Efferent connections of the striate cortex in the albino rat. Journal of Comparative Neurology, 1954, 100, 257-286.

Penfield, W. Memory mechanisms. Archives of Neurology \& Psychiatry, 1952, 67, 178-198.

Penfield, W. Studies of the cerebral cortex in man: A review and an interpretation. In J. F. Delafresnaye (Ed.), Brain mechanisms and consciousness. Springfield, Ill: Thomas, 1954.

Petit, T. L. The functional significance of the nucleus cuneiformis for the retention of visual pattern discriminations in the white rat. Unpublished masters thesis, Louisiana State University, 1972.

Runnels, L. K., Thompson, R., \& R unnels, P. Near-perfect runs as learning criterion. Journal of Mathematical Psychology, $1968,5,362-368$.

Schweigerdt, A. K. The role of the ventral mesencephalon in the learning of three visual habits in the rat. Unpublished doctoral dissertation, Louisiana State University, 1969.

Thompson, R. Centrencephalic theory and interhemispheric transfer of visual habits. Psychological Review, 1965, 72, 385-398.

Thompson, $R$. Localization of the "visual memory system" in the white rat. Journal of Comparative \& Physiological Psychology Monograph, 1969, 69, 1-29.

Thompson, R., \& Bryant, J. M. Memory as affected by activity of the relevant receptor. Psychological Reports, 1955, 1, 393-400.

Thompson, R., \& Craddock, S. N., Jr. Lateral cerebral peduncle lesions: Amnestic effects on a visual habit in the rat. Psychonomic Science, 1972, 27, 140-142.

Thompon $R$ Duke, $R$ B Malin, C. F \& Hawkins, E. F. The Interpeduncular nucleus and retention in albino rats. Journal of Comparative \& Physiological Psychology, 1961, 54, 329-333.

Thompson, R., \& Henderson, T. C. Pontine reticular formation lesions: Amnestic effects on learned habits in the rat. Psychonomic Science, 1971, 25, 169-170.

Thompson, R., Howze, M. A., \& Pucheu, J. H. The lateral pedunculonigral area and visual pattern discrimination performance in the white rat. Bulletin of The Psychonomic Society, 1973, 2, 83-84.

Thompson, R., Lukaszewska, I., Schweigerdt, A., \& McNew, J. J. Retention of visual and kinesthetic discriminations in rats following pretecto-diencephalic and ventral mesencephalic damage. Journal of Comparative \& Physiological Psychology, $1967,63,458-468$.

Thompson, R., Rich, I., \& Langer, S. K. Lesion studies on the functional significance of the posterior thalamomesencephalic tract. Journal of Comparative Neurology, 1964, 112, 29-44.

Valverde, F. Reticular formation of the albino rat's brainstem cytoarchitecture and cortifugal connections. Journal of Comparative Neurology, 1962, 119, 25-53.

Winer, B. J. Statistical principles in experimental design. New York: McGraw-Hill, 1962.

\section{NOTES}

1. Thompson, R., Howze, M. A., \& Petit, T. L. Midbrain areas necessary for visual pattern discrimination performance in the rat, in preparation.

2. Following overtraining on the last problem (visual or kinesthetic) five randomly selected Ss (three brain-damaged and two control) were anesthetized and underwent enucleation of the eyes. After a three-day recovery period, the Ss were again required to attain criterion on the kinesthetic problem using the same procedure employed in acquisition. All five Ss attained criterion without making a single error. This demonstrates that 
cues other than visual were used in acquisition of the kinesthetic habit.

3. Most optic fibers from the visual cortex have left the cer ebral peduncle and entered the brainstem by this point.

4. The assumption of homogeneity of variance is often not met in repeated measures designs and was not met in this study.
However, Box (1953) reports that heterogeneity of variance has little effect on the analysis of variance.

(Received for publication March 26, 1974; revision received August $6,1974$. ) 